\title{
Geoscience provides assets for sustainable development
}

1 Technical University Delft, Fac. of Civil Engineering, P.O. Box 5048, 2600 GA Delft, and NITG-TNO, National Geological Survey, P.O. Box 157, NL-2000 AD Haarlem, the Netherlands,

2 Institute of Geosciences, University of São Paulo, P. O. Box 11348, 05422-970 São Paulo, Brazil

\begin{abstract}
The UNCED Environmental Conference in Rio de Janeiro 1992 has changed the world. Geoscientists entered the environmental field relatively late, however, geological surveys and geoscientific research institutes adapted to this situation and have placed geo-environmental issues high on their agendas. This paper discusses their role against the background of the most relevant issues in 'sustainable development' for the next decade. These include water, soil, poverty alleviation, urbanisation, waste disposal, energy, minerals, disaster reduction and education. Although geoscientists cannot prevent nor cure all of the world's major problems, their ability to cope with long time and wide space scales together with their advanced technologies can and must contribute to solving many of society's problems. This, however, requires a new and untraditional type of geoscientist.
\end{abstract}

\section{Geosciences and the environment}

Geoscientists entered the environmental scene rather late. They were preceded in this field by engineers, geographers, biologists, climatologists, oceanographers and scientists from several other disciplines. This has not been beneficial for the geoscientists' position in general and for their representation in major applied scientific bodies and research programmes in particular. Earth scientists could only pick among the leftovers and from those topics which could not be covered by other disciplines. Despite of this late start, many geoscientists are now heavily involved in environmental issues and both the volume and scope of their contribution in environmental programmes are increasing. The governmental concern for safe storage of high-level radioactive waste material, for example, has boosted applied geoscience in many research centres world-wide and encouraged such centres to put more emphasis on the environmental aspects of the earth sciences. Such developments have also affected the structure of Geological Surveys (Babcock, 1994; Cook et al., 1996).

In this paper some observations are made on the current involvement of earth scientists in environmental issues followed by a prognosis on how such involvement may develop in the next decade. Large international bodies such as the European Union responded to the increased environmental concern somewhat later than many countries did on a national level. The European Union launched the European Environmental Agency (in Copenhagen) in 1993. The involvement of the European Union in environmental matters is reflected in the growth of their budget for environmental research over the successive 4-year framework programmes. Prior to
UNCED (1992), United Nations developed a financial instrument to support major environmental research and development programmes. In 1994 this Global Environment Facility (GEF) had a budget of over 2 billion US\$ and 150 countries participated. Other regional UN bodies such as the Economic and Social Committee of Asia and the Pacific (ESCAP) monitor the state of the environment in the region of their member countries. Such 'State of the Environment' reports are produced every five years and progress and constraints are discussed during Ministerial Conferences (ESCAP, 1990).

Towards the end of the Eighties the question whether specific emphasis should be put on environmental issues was discussed in international geoscientific unions and associations. These debates resulted in the creation of a new Commission in the International Union of Geological Sciences (IUGS) on Geological Sciences for Environmental Planning (COGEOENVIRONMENT) in 1990. This Commission developed strong links with other international bodies ensuring that overlap was limited (de Mulder, 1994). Another example of addressing the environmental issue by IUGS was the launch of 'Partnership for Earth Management' sponsored by the International Council of Scientific Unions (ICSU) (Fyfe \& Caldwell, 1996). Such developments marked a rather fundamental shift in both scientific concepts and in the daily work of many earth scientists. In his paper Fyfe (1997) also addresses the issue of geoscientific input for sustainable development.

\section{Geosciences and sustainable development}

Public concern over global environmental change and the likelihood of the Earth remaining a healthy environment for future generations is commonly expressed in the phrase 'sustainable development'. Valuable information on econometric aspects of 'development', specifically in developing countries is for instance given by Goldemberg (1996). Because earth scientists are used to dealing both with development and with the environment and are especially capable of viewing global environmental change in correct spatial and time frameworks, they are particularly well equipped to contribute to 'sustainable development'. Requirements and issues for arriving at sustainable development often contain Earth-related aspects. Therefore, it is advisable that earth scientists are involved in realising such requirements, preferably alongside experts in other scientific and non-scientific disciplines (Cordani, 1998). These requirements and issues include: water, soil, urbanisation, waste disposal, energy, minerals, and disaster reduction. Geoscientific aspects of these key requirements for sustainable development are described below.

\section{Water}

In numerous recently published state-of-the-environment reports, water turns out to be the factor most limiting sustainable development. In the next decade the availability of fresh water will 
dictate all agendas of development, not only in developing countries, and might cause political instability in larger dry regions on Earth. Peace agreements in the Near East, for example, invariably include major chapters on regional water management. The availability of fresh potable water is seriously restricted by: 1) depletion of aquifers and 2) pollution of both surface and groundwater resources. The problem of aquifer depletion is partly caused by inadequate aquifer management (over-exploitation, poor recharge, etc.) but mainly by the fact that ever-smaller quantities of fresh groundwater will have to supply more and more people on earth.

As professional explorers, geoscientists can assist in mitigating aquifer depletion by identifying new fresh, often deeply seated and more remotely situated groundwater resources. Geoscientists can also be involved in upgrading groundwater management by optimising the spatial distribution and extraction depths of groundwater wells. They are well equipped to detect and delineate pollution flumes in aquifers and their potential propagation through the system.

At first sight, the role of geoscientists in preventing pollution of groundwater and surface water resources may be less obvious. However, their three-dimensional knowledge of the earth's structure, its composition and that of the sediment/rock properties, together with their knowledge on the sediment-groundwater interaction, allows them to feed groundwater-flow models that simulate flow paths with sound data and to calculate the retention capacities of strata to certain polluting elements. Geo-forecasting has become a very promising tool for water management and can lead to measures that will prevent valuable aquifers from being contaminated (further).

\section{Soils}

Agricultural soils are seriously under threat. The formation of agricultural soils is a slow process taking place at the rate of a few millimetres per year. Man's activities such as deforestation, poor or totally absent land-use management techniques (e.g. slash and burn), and inadequate or excessive use of fertilisers and agrotoxics, have resulted in extensive soil losses or soil degradation. In the People's Republic of China 5 billion tonnes of fertile soil is lost annually, 2 billion tonnes of which is transported by rivers and deposited in oceans or in lakes. This equals 1/12th of the world's total $(\mathrm{Li}$ Lierong, 1992). Other types of land loss are desertification and salinisation. The equivalent of 5 to 6 million hectares of soil is lost every year, making soil erosion one of the worst factors limiting sustainable development (Norse, et al., 1992). Overall, sustainable agriculture can only be achieved when soil erosion and degradation do not exceed replacement. At human time scales and with the current practices soil has become a non-renewable resource and a fundamental constraint to sustainable development.

Geoscientists may apply their knowledge of the fluvial and marine/coastal processes to contribute to the understanding of the local and regional problems and thus predict and pinpoint jeopardised areas of fertile land. Application of erosion models could help to design planning and management systems to prevent fluvial and coastal (soil) erosion.

\section{Urbanisation}

$50 \%$ of the Earth population lives in cities that cover only a few percent of the total land surface of the globe. 'Sustainable urban development' is therefore a matter of high priority on the international environmental agendas. The concentration of high-rise buildings, underground structures, steep slope cuts, excessive groundwater extraction poses large differential stresses on relatively small areas of land, causing imbalance and creating major geo-hazards (de Mulder et al., in press).

Urban geologists collect and process subsurface data and communicate their three dimensional view on the city's subsurface to urban managers and planners. When economic and legal data are added, reliable, but indicative cost/benefit analyses can be provided. Subsequently, site selection can be based on unbiased data through decision-support systems. Such systems may provide transparent tools understandable for urban managers and for the ever more concerned urban public. Urban geoscientists have joined to form the International Working Group on Urban Geology. This body provides scientific support for the Forum on Urban Geology in Asia and the Pacific (FUGAP) and for the GEURBAN network on Urban geology for the Geological Surveys of the European Union and Norway (de Mulder, 1998).

\section{Waste disposal}

Poor waste management often seriously obstructs sustainable development. The over 40-metre-high waste dump ('smoky mountain') of Manila in the Philippines presents a major threat to the environment in and around this megacity (ESCAP, 1990). Domestic waste is mostly stored on or near the surface near or in the immediate vicinity of urban centres. Too often such waste dumps are poorly designed and lack an adequate lining underneath the dump site (Han Daesuk, 1995) and/or are situated on permeable beds allowing leachate to enter the aquifers. Studies on storing waste materials are generally limited to the engineering aspects of preselected sites. The availability of natural geological barriers preventing transport of contaminants into aquifers is taken into account only occasionally.

Sustainable waste disposal is more and more based on the 'multi-barrier' principle, taking into consideration impermeable or poorly permeable beds such as thick clay bodies, rock salt or shales as the last (natural) barrier to leachates before entering into the biosphere. This particularly applies to highly toxic radiation waste such as high-level radioactive waste. The generally very strict site-assessment procedures used for this waste category, however, often do not apply for other types of waste, even if this concerns highly dangerous and everlasting chemical waste materials. Sites for radioactivewaste disposal are generally selected for logistic, administrative and political reasons.

Another factor obstructing radioactive-waste storage is the policy that such waste has to be stored in a country's or province's own territory. There is, however, no guarantee that a suitable site can be found there and a less appropriate site may then be selected. The enormous potential environmental impact of such hazardous waste in the long term provides a good enough argument in itself to question this policy and to search for premium sites even if these are not in the national territory. If one considers the dramatically changed positions of national borders in a continent such as Europe over the past two centuries only, the current solely national studies on radwaste disposal which should be safe for at least 10,000 years (e.g. USA), 100,000 years (e.g. Germany, the Netherlands) or one million years (e.g. Sweden) lack a well-considered and realistic time/space concept. The study by the International Union of Geological Sciences (IUGS) under the aegis of the International Council of Scientific Unions (ICSU) for the best possible site for permanent storage of radioactive waste is therefore welcomed.

Waste management will become increasingly important in the coming years. Although it is expected that eventually less waste will be produced per person in a more developed world, an increase in waste production in the less developed world cannot be avoided during the next few decades. It will probably not take long before multinational companies will employ both exploration and environmental geoscientists in their efforts to find places where such waste can be stored in an environmentally sustainable and cost-effective way.

\section{Energy}

Non-renewable energy resources such as oil and natural gas are being gradually but irrevocably depleted. In view of the fact that the need for energy keeps pace with population growth, an annual energy need of 630 Gigajoules/year is foreseen in 2020 (Meadows et al, 1992). Consequently, it is evident that the search for and wise use of energy resources deserves a prominent position in development agendas. This concern, however, is not reflected in the energy price in most countries which 'subsidise' energy delivery through a sys- 
tem of low taxes. If environmental resource accounting were applied fully to oil and gas, prices would be increased considerably in e.g. the U.S.A. This, in turn, might discourage excessive and wasteful use of these valuable resources. Very large resources of black and brown coal still exist in the earth. These resources are predominantly mined and utilised in developing countries, causing massive $\mathrm{CO}_{2}$ emission. In addition, large quantities of $\mathrm{CO}_{2}$ are emitted into the atmosphere by spontaneous coal combustion. Such "coal fires" occur frequently in China, India, and Indonesia and consume 100200 million tonnes of black coal in China every year. Geoscientists are currently involved in combating these major environmental problems (Schalke, 1993). They are also involved in studies on the storage of large volumes of this greenhouse gas in depleted natural gas reservoirs. Techniques have become available of producing natural methane gas from buried coal beds in a more environmentally friendly way or by controlled underground coal combustion. A great challenge for the earth science community in the coming decades will be the exploitation of solid methane hydrates occurring at great depths particularly in the ocean floors and under permafrost areas and holding enormous potential energy resources.

In large regions of the world people rely almost entirely on wood for fuel causing deforestation which clearly has a negative impact on the environment through reduction of $\mathrm{O}_{2}$ production, reduction of biodiversity, increased soil loss and erosion, excessive sedimentation and landslides. Geoscientists can predict such environmental problems and assist planners to develop less harmful solutions.

\section{Minerals}

Governments are increasingly concerned about the environmental impact of the mining industry and impose severe environmental constraints on mining activities. As a result, for instance, Canadian copper mining companies moved to Chile. Environmentally sustainable mining is expensive whereas mineral prices are still low. Only mining of high-grade ores can be economic and then only on very large scales. To find such sites requires great expertise in exploration and thus geological skills. The same applies to relatively cheap aggregates and construction materials. In densely populated countries such as the Netherlands, combined extraction pits for both clay and coarse sand are becoming increasingly common, consequently the landscape is spoilt less (de Jong \& de Mulder, 1998).

To assess the geochemical impact of mining and the environmental impact of its tailings, geoscientists are needed as well. They may contribute to the development of adequate chemical, physical or biological ex-situ and in-situ remediation methods for polluted or unstable tailings. In addition, geoscientists can play a key role when it comes to environmental monitoring because they are familiar with the geochemistry of mining. To this end it is essential to measure the original background values of the soil geochemistry. Since these are closely connected with the natural geological conditions of rocks and soils, establishing a reliable picture of the zero levels should essentially be the job of geoscientists (Darnley et al., 1995).

\section{Disaster reduction}

In the framework of the International Decade of Natural Disaster Reduction of the United Nations (1990-1999) annual reports have been compiled on the impact of the world's natural disasters. Such reports show e.g. that in the period 1990-1993, 237,737 people were killed or reported missing as a result of natural disasters, such as earthquakes, floods and landslides. The total economic losses caused by these disasters in that period exceeded 200 billion US\$, which is about $0.2 \%$ of the world's Gross Product (Ayala Carcedo, 1994).

The results of assessing and monitoring the impacts of natural and man-induced disasters/hazards clearly demonstrate the need for prediction and prevention tools. As geological processes form the basis for calculating the effects of such hazards, prediction models should inevitably be based on geoscientific expertise. While such predictions were mainly qualitative in the past, an increasing number of Earth processes have been approached in a mathematical-physical way during the past decade, leading to the development of steadily improving numerical models. Such models can now simulate the future effects of certain geological processes under varying conditions.

Other hazards are related to global change as a result of the increased emission of greenhouse gases. As global change problems encompass the entire Earth including its geosphere, hydrosphere, biosphere and atmosphere, an integrated approach which considers the Earth as a single system is now preferred. Geoscientists currently contribute to studies concerning the anticipated harmful effects of global change. Firstly, the climatic effects of varying amounts of such gases under natural conditions in the atmosphere during the geological past are now studied by many Quaternary geologists. They participate through the International Union for Quaternary Research (INQUA) in the PAGES (Past Global Changes) Core Project of the International Geosphere-Biosphere Programme. Such studies have for instance resulted in considerably more precise dating of past climatic events and to a much better understanding of the natural increase and decrease of greenhouse gases in relation to glacial and warm periods both on time scales of 200,000 and 2,000 years.

Another aspect of global change concerns the impact of an accelerated sea-level rise on the present-day coastal zones. In this respect it has become clear that only an integrated approach taking into account the interests of all stakeholders in such regions, can lead to reliable predictions concerning the areas which are threatened by marine flooding. Global change will not only affect sea levels but also climatic conditions in monsoon areas. Studies in the INQUA/PAGES framework have demonstrated that substantial shifts in the climatic zones in monsoon areas have occurred in the recent geological past and will probably occur again in the near future (Kroepelin, 1994). Promising results have been achieved by geoscientists in studies on the Carbon Cycle which quantify the volume of Carbon lost in sinks and that produced in the sources of the Earth System as an approach to estimating the contribution of natural $\mathrm{CO}_{2}$ to the atmosphere (Faure et al., 1994, Jiang Zhongcheng \& Yuan Daoxian, 1999).

It is becoming increasingly clear that the great efforts in developing global climate models will have been in vain if these are not fed with and evaluated against reliable geological data. Often poor modelling results have forced modellers to contact geoscientists to provide such data.

\section{Socio-economic aspects of development}

Apart from the listed environmental requirements for sustainable development, several major and general socio-economic issues also need geoscientific input to achieve sustainable development.

\section{Poverty alleviation}

UNDP considers poverty alleviation the most important factor in achieving sustainable development (UNDP, 1995). Poverty is the driving force of land degradation because it induces unsustainable land-use practices. Furthermore, 'real' sustainable development can only be approached when ethical principles of human solidarity are applied (Cordani, 1998). Poverty alleviation is often seen as a social issue only. However, several aspects of poverty mitigation, such as health and safety, should be regarded by more physically oriented disciplines, among which are the geosciences. Several health problems are directly or indirectly related to the geological conditions of the area where people live, particularly in developing countries. Such issues are now addressed by geoscientists and the medical sector together (Fyfe, 1997; Plant et al., 1998; Selinus, 1996). 


\section{Education}

Population growth and poverty are strongly associated with illiteracy (Goldemberg, 1996). Thus, one of the basic tools to combat poverty and population growth is elimination of illiteracy. Education is therefore one of the key elements for arriving at sustainable development. New development models requiring all available knowledge and co-operation between all target groups, have been designed in the past decade. An example of such a model is 'Integrated Coastal Zone Management' in which all factors in the coastal zone are involved in the decision-making process. This model is fed with all kinds of information, including earth-scientific information and has a strong emphasis on environmental elements. For this shift in approach re-education is needed, not only for the young generation but for people at management levels as well. A similar approach is needed for studying the impacts of Global Change on the hydrosphere, geosphere, biosphere and atmosphere. This again puts strong pressure on the educational system which should basically be modified from discipline-oriented to integrated science studies (Faure et al., 1993). To solve environmental problems, the geosciences should be fully integrated with other disciplines. If we would modify the educational systems and adopt new curricula, future students will become familiar with problem solving in an integrated way from the start.

\section{The next decade}

In the previous chapter, several vital elements of the (potential) role of earth scientists have been described that are necessary to arrive at sustainable development. Now the question arises: Which present trends are likely to continue for at least the next decade? And what should be the role of earth scientists in these fields? On the basis of what has been discussed above, the following negative trends are foreseen:

- growing population

- increased urbanisation

- depletion of potable water, fertile soils and other resources

- increased poverty.

The first two trends are expected to occur predominantly in the third world while the last two may occur everywhere on this planet.

On the positive side, however, we can note:

- increased environmental awareness and concern

- growing development of 'clean' technologies

- less political dogmatism

- improved cross-border communication.

In sum this means that human activity has reached a scale which may influence the stability of the earth itself, jeopardising the lives and properties of its people. This also means that more of us are ready to think and communicate globally and have better tools and possibilities to act locally.

Earth scientists cannot prevent nor mitigate all the world's problems in the next decade, nor afterwards. However, their highly sophisticated in-depth site-, surface- and space-surveying techniques and improved knowledge of geological processes, enable geoscientists to develop very detailed 3-D and 4-D (including time) pictures of the Earth's subsurface conditions, including rock and soil properties. Furthermore, they can presently assess natural and man-induced modifications in the state of the environment through environmental geo-indicators (Berger \& Iams, 1996). In contrast to the past, data can now be presented in a quantitative way and can thus be used almost directly as input for advanced geo-simulation models. An important boundary condition for these developments is linking of databases. Such simulation models can for instance generate approximations of future ground behaviour according to pre-set scenarios. Such approximations are necessary for Environmental Impact Assessments and for Decision Support Systems, which will probably become regular tools in the decision-making process within a decade.
Which targets and job opportunities will emerge for earth scientists in the next decade? If we focus on non-renewable metallic and energy resources we will probably face exploration for large, deep-seated resources of superior quality wherever they occur, even in poorly accessible areas, such as the Amazon Basin, ocean floors and permafrost areas. This demands highly specialised geoscientists familiar with wide ranges of very sophisticated exploration techniques. Some authors foresee a reduction by as much as $90 \%$ in the consumption of primary materials in the next five decades in the (present-day) industrialised countries (Schmidt-Bleek \& Bringezu, 1994). On the other hand, large volumes of other, now less wanted minerals will be needed for the construction of new materials developed by new generations of metallurgists, which will have a positive effect on the job market for geoscientists. Opportunities are foreseen for biogeochemists dealing with microbiological production of metals in laboratories or in mines.

The increased population density will generate a much higher demand for fresh groundwater in and around cities. Groundwater exploration companies will employ larger numbers of geoscientists. Further depletion of non-renewable or hardly renewable resources, such as fertile soils, will undoubtedly be another topic for earth scientists in the next decade. This will require engineering and environmental geologists specialised in pedology and landslide prevention, geochemists, geomorphologists and mineralogists specialised in mitigating degraded soils (as a result of salinisation, desertification, etc.) and in remediating collapsed soils and mine tailings with poor foundation qualities. Remediation of contaminated soils is a prominent issue now and will continue to be in the next decade. New remediation techniques based on a better understanding of the contamination processes but also of the biogeochemical characteristics and processes in the subsurface (e.g. natural attenuation) will also provide jobs for broadly specialised geoscientists in the coming years.

Environmental geology and engineering geology (s. 1.) are the disciplines which are also most obviously involved in hazard prediction, hazard prevention and hazard mitigation, all of which are expected to be major issues in the next decade as well. Increased population density creates higher risks for geological hazards. It is anticipated that companies, organisations and private persons facing high potential losses will become increasingly interested in insuring against such risks. In that perspective, insurance companies will need reliable geo-information and already involve geoscientists in this.

Where the 20th century was characterised by exploiting the air space and atmosphere, the 21 st century will witness large-scale exploitation of subsurface space, particularly so in the densely populated delta areas. More land will be reclaimed in the coastal zones and losses of lives and property due to natural hazards will be reduced significantly due to the increased application of geoscientific expertise. Practically oriented earth scientists must and will be involved in such developments.

\section{Value of geoscience for sustainable development}

The listed requirements for environmentally sustainable development show that geoscientists will have a significant role to play, both in the next decade and beyond:

1. Geoscientists can contribute to the alleviation of the anticipated shortage of fresh water by finding new underground resources, by optimising groundwater exploitation, by creating new aquifers through land reclamation and natural recharge, and by forecasting flow paths of pollutants in aquifers.

2. Geoscientists can contribute to the mitigation of the foreseen reduction in fertile land area by developing measures to prevent soil loss both as a result of erosion and of soil contamination.

3. Geoscientists can contribute to the prevention of the negative effects of uncontrolled urbanisation by finding new resources (fresh 
water, fertile soils, construction and energy materials, minerals, etc.) for the citizens, by predicting natural and man-induced hazards and warning the municipal authorities of unstable and/or risky areas, by assisting in the selection of optimal sites for urban expansion and urban land use and by developing urban geo-information systems and decision-support systems to assist urban planners, developers and to inform the citizens.

4. Geoscientists can contribute to selecting suitable sites for waste dumps, either underground, in the ground or on the surface, by identifying appropriate, natural, geological barriers which will last much longer than the best geotextiles, by predicting potential contamination patterns, by applying the geologically determined natural attenuation capacity of deposits in the subsurface, and in the development of geo-remediation strategies.

5. Geoscientists can contribute to solving the world's energy problems by finding new resources, by developing methodologies for unconventional energy production in e.g. underground coal beds, by reducing wastage of energy resources during production, storage and transport, or by combating 'coal fires'. In addition, they can contribute to mitigating the negative effects of energy production by predicting the environmental impact of the unsustainable use of energy resources, by assessing potential sites where radioactive waste or $\mathrm{CO}_{2}$ can be safely stored underground.

6. Geoscientists can continue to substantially contribute to the economy by finding new mineral resources. In addition, they can contribute to the mitigating of the negative effects of mining and mineral processing by predicting the environmental impact of such activities, by applying such information for environmentally sustainable siting of plants and (super)quarries, and by developing and applying proper (biogeo-)remediation methodologies.

7. Geoscientists can further contribute to disaster reduction by predicting geo- and man-induced hazards and their impact on society, by constructing hazard zonation maps, by alerting authorities to the effects of global change, such as geologically realistic estimates of sea-level rise and droughts. They can also contribute by developing mitigation methods and early warning systems.

8. Geoscientists can even contribute to poverty alleviation and to arrive at a better public health situation by exploring for unpolluted, fresh water resources for the poor, by promoting integrated coastal zone and land management taking into account the demands of the poor, by mitigating land deterioration resulting in higher crop yields, and to a safer housing situation by reducing potential geohazards.

9. Finally, geoscientists can contribute to improved education by supporting environmental education programmes both at grassroots level and at the level of planners and politicians, e.g. through educating local decision-makers in the geological background of natural and man-induced hazards. Increasing awareness of the essential role geosciences can play in environmental planning and management, will also contribute to the general education level of people.

\section{Conclusions}

Geoscientists can and must contribute to solving the basic problems of mankind in the next decade, even more than today. The targets and job markets for geoscientists will shift from the traditional exploration sector towards the service sector. A new type of geoscientist is emerging: client-oriented geo-clerks with broad, multidisciplinary backgrounds including non-geoscientific topics and information technology, who will not solely focus on a geological approach for problem solving, but who will try to develop a total solution from a holistic approach.

\section{Acknowledgements}

The authors wish to thank William S. Fyfe and Robin Brett for their suggestions and interest in the paper. The editorial work by Cor van Staalduinen is greatly appreciated.

\section{References}

Ayala Carcedo, F.J., 1994, Natural Disasters in the World, 1993: Geoenvironmental engineering, GeoMining Technological Institute of Spain, Madrid.

Babcock, E.A., 1994, Geoscience in a changing society: Episodes, vol. 17, no. 4, pp. 101-105.

Berger, A.R. \& W.J. Iams, 1996, Geologic indicators of rapid environmental change: Balkema, Rotterdam.

Cook, P.J., Mulder, E.F.J. de \& M. Temmes, 1996, New Challenges for geoscience in society; international evaluation of the Geologian tutkimuskeskus (GTK): Min. of Trade \& Industry, Finland. ISBN 951 7391943.

Cordani, U.G., 1998,Geosciences and devepoment: The role of the Earth Sciences in a sustainable world: Ciência e Cultura, vol.50, no.5, pp. 336-314.

Darnley, A.G., Björklund, A., Bølviken, B., Gustavsson, N., Koval, P.V., Plant, J.A., Steenfelt, A., Tauchid, M. \& Xie Xuejing, 1995, A Global Geochemical Database for Environmental and resource Management: UNESCO, Earth Sciences 19.

ESCAP, 1990, State of the Environment in Asia and the Pacific. New York.

Faure, H., Faure-Denard, L., \& Tungsheng Liu, 1993, Introduction to Quaternary Earth System Changes: Global and Planetary Change, 7, VII-IX, Elsevier Science Publ., Amsterdam

Faure, H., Velichko, A.A. \& J.M. Adems, 1994, The influence of the terrestrial system on the global carbon cylcle during the late Quaternary: First GCTE Science Conference, Woods Hole, USA.

Fyfe, W.S., 1997, Earth System Science for the 21rst Century: towards truly sustainable development: Episodes, vol. 20, no. 1, pp. 3-6.

Fyfe, W.S. \& W.G.E. Caldwell, 1996, Earth Sciences and global development- an IUGS Perspective. Episodes, vol. 19, no. 1 and 2: 21-23.

Goldemberg, J., 1996, Energy, Environment \& Development. Earthscan Publications, London.

Han, Daesuk, 1995, Case history: Landfills for urban waste disposal in and near the city of Seoul. Mineral Recovery, recycling, waste prevention and confinement for sustainable development in Asia and the Pacific Region: Resource Assessment, Development and Management, vol. 1, pp. 132-138, ESCAP, Bangkok, ST/ESCAP/1554.

Jiang Zhongcheng \& Yuan Daoxian, 1999, $\mathrm{CO}_{2}$ source-sink in karst processes in karst areas of China. Episodes, vol. 22, no. 1, pp. 33-35.

Jong, B. de \& E.F.J. de Mulder (1998), Construction Materials in the Netherlands: Resources and Policy. in P. Bobrowsky ed. Aggregate Resources, Balkema, Rotterdam.

Kroepelin, S., 1994, Paleomonsoons in Africa and Surrounding Oceans: the Last 200,000 years: Proc. INQUA-PAGES Workshop. PAGES Workshop Report, ser. 94-2, Bern, Switserland.

Li Lierong, 1992, Geoscience for the environment in China: Newsletter COGEOENVIRONMENT, 1, pp. 8-10. Haarlem, the Netherlands.

Meadows, D.H., Meadows, D.L. \& Randers, J., 1992, Beyond the Limits: Global Collapse or a Sustainable Future? Earthscan Publications, London.

Mulder, E.F.J. de, 1994, Geoscience for Environmental Planning and Management: An international perspective: Proc. 7th Int. Congr. Int. Ass. Engineer. Geol.: 2337-2341, Balkema, Rotterdam.

Mulder, E.F.J. de, 1998, What has GEURBAN done? Episodes, vol. 21, no. 3, p. 197.

Mulder, E.F.J. de, McCall, G.J.H. \& B.R. Marker, (in press), Geoscience for Urban Planning and Management: Proc. I.A.E.G. Congress, Athens. Balkema, Rotterdam.

Norse, D., James, C., Skinner, B.J., \& Zhao, Q., 1992, Agriculture, Land-Use and Degradation, in An Agenda of Science for Enviromenta and Development into the 21st Century: ICSU, University Press, Cambridge.

Plant, J.A., Baldock, J.W., Haslam, H.W. \& B. Smith, 1998, The role of geochemistry in environmental and epidemiological studies in developing countries: Episodes, vol. 21, pt. 1, pp. 19-27.

Schalke, H.J.W.G., 1993, Spontaneous Coal Fires, a geological hazard with global impact: Newsletter COGEOENVIRONMENT, IUGS, Haarlem. 
Schmidt-Bleek F., \& S. Bringezu, 1994, The use of mineral resources and sustainable development: problems and perspectives from an ecological point of view. Mineral Resources and sustainable development: a workshop: Techn. Rep. WF/94/12, pp. 56-58. British Geological Survey.

Selinus, O., 1996, Large-scale monitoring in environmental geochemistry. Applied Geochemistry, vol. 10., pp. 1-10.

\section{Eduardo F. J. de Mulder is Head of} the Geo-Infrastructure Department of the Netherlands Institute of Applied Geosciences, the National Geological Survey and Professor in subsurface management in Delft Technical University. He is the Chairman of the IUGS Commission on Geological Sciences for Environmental Planning, Treasurer of the International Union of Quaternary Research and Chairman of the European topic network on Urban Geology. He is author of 80 scientific papers and books.
Umberto G. Cordani, former President of IUGS (1988-1992), graduated in Geology at the University of Sao Paulo (USP), Brazil, where he made a complete academic career up to the position of Full Professor in 1980. He was Director of the Institute of Geosciences and of the Institute of Advanced Studies in the same University, where he presently occupies the position of Chairman of the International Cooperation Commission.

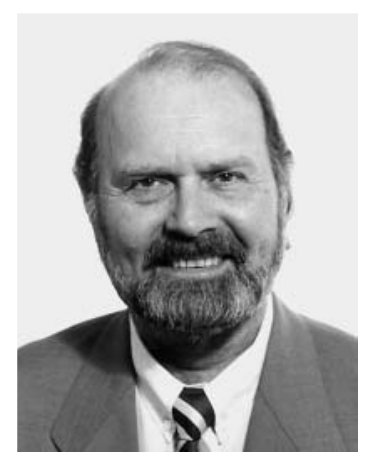

\section{Hutchison 'Young Scientist' Fund}

William Watt Hutchison, "Hutch" to his many friends around the world, was a Scots-born Canadian geologist who served Canada and the IUGS in myriad dynamic and creative ways. Most notably, he served as the IUGS Secretary General (1976-1980) at a pivotal time in its history, and as IUGS President (1984-1987). The same boundless energy, enthusiasm, skill in communications, and ability to foster teamwork that characterized his work with the IUGS also carried him to preeminent scientific administrative positions in the Canadian Government, where he served as Director General of the Geological Survey of Canada and as Assistant Deputy Minister of Earth Sciences. His distinguished career was terminated in 1987 by his untimely death at the age of 52, following a painful struggle with cancer.

One of Hutch's last wishes was to establish under IUGS auspices a memorial foundation intended to promote the professional growth of deserving, meritorious young scientists from around the world by supporting their participation in important IUGS-sponsored conferences. The first 3 beneficiaries of the Hutchinson "Young Scientist Foundation" attended the 28th International Geological Congress (IGC) in Washington, D.C., in 1989.

Currently, income earned as interest on the Hutchison fund is insufficient to sustain comparable grants every four years without seriously eroding the principal. For that reason, the IUGS made no grants from the fund for the 30th IGC, preferring instead to strengthen the fund by allowing it to earn interest for a longer period of time and by appealing for donations from the international geologic community. It is expected that grants from the fund will again support deserving young scientists to attend the 31st IGC in the year 2000. The Hutchison "Young Scientist Foundation" is a worthy cause that honors a fine, caring man and a distinguished, public-spirited scientist and administrator. The foundation also celebrates and promotes those things that gave Hutch the most professional satisfaction: geology, international scientific collaboration, and stimulating young minds.

The IUGS welcomes contributions to the Hutchison "Young Scientist Foundation." Please send donations to:

$$
\begin{aligned}
& \text { Dr. John A. Reinemund } \\
& \text { P.O. Box 890 } \\
& \text { Leesburg, VA } 20178 \text { USA } \\
& \text { Fax: +1 } 7037774463 \\
& \text { Tel: +1 } 7037771491
\end{aligned}
$$

Checks in US dollars or Visa/Mastercard (please include account number and expiration date) are preferred in order to avoid the high cost of currency conversions. Residents of the U.S.A. are reminded that charitable gifts of this nature are tax deductible. 